\title{
GEOGRAPHICAL FACTOR IN REGIONAL DEVELOPMENT ${ }^{1}$
}

\author{
Marina V. Moroshkina \\ Institute of Economics of the Karelian Scientific Center of the Russian Academy of Sciences, \\ Petrozavodsk, Russian Federation
}

\begin{abstract}
Regional development of Russian regions is characterized by a high level of heterogeneity. Researchers highlight a significant number of factors affecting the level of regional development. Geographical factor is recognized as one of the most important factors. The development of border regions is similar to that of Russian regions. The purpose of the research is to determine the differentiation of border regions and to study the dynamics of its change. The object of the research is border regions united in the system. The process of unification of regions is based on geographical location. The subject of the study is the process of regional differentiation. Methods of assessing the convergence of economic entities are the instrument of researching regional differentiation of border regions. The convergence theorem analyzes the interregional differentiation of border regions and considers the possibility of their convergence. As a result of using convergence approaches based on the definition of convergent processes, the coefficient of variation is calculated. On the basis of the calculated values of the coefficient and its change, the possibility of convergence of border regions is assessed and the process of change of interregional differentiation is analyzed. Another direction, on the basis of which the analysis of regional heterogeneity of border regions is based, is the determination of the differentiation coefficient, which allows to determine the level of the gap between polar groups of regions. The goal set in the study will allow assessing the impact of geographical location on economic development and formulating directions of economic policy. Spatial heterogeneity of border regions defined by means of mathematical tools can be used when writing the Program and the Strategy for Regional Development, within which one of the competitive advantages will be the location of the territory.
\end{abstract}

Key words: border regions, spatial heterogeneity, interregional differentiation, coefficient of variation, $\alpha$-convergence, differentiation coefficient, lagging behind border regions, leading border regions.

Citation. Moroshkina M.V. Geographical Factor in Regional Development. Journal of Volgograd State University. Economics, 2019, vol. 21, no. 4, pp. 90-98. (in Russian). DOI: https://doi.org/10.15688/ek.jvolsu.2019.4.9

УДК 332.1

Дата поступления статьи: 01.08.2019

ББК 65.9 Дата принятия статьи: 03.09.2019

\section{ГЕОГРАФИЧЕСКИЙ ФАКТОР В РЕГИОНАЛЬНОМ РАЗВИТИИ ${ }^{1}$}

\author{
Марина Валерьевна Морошкина \\ Институт экономики Карельского научного центра РАН, г. Петрозаводск, Российская Федерация
}

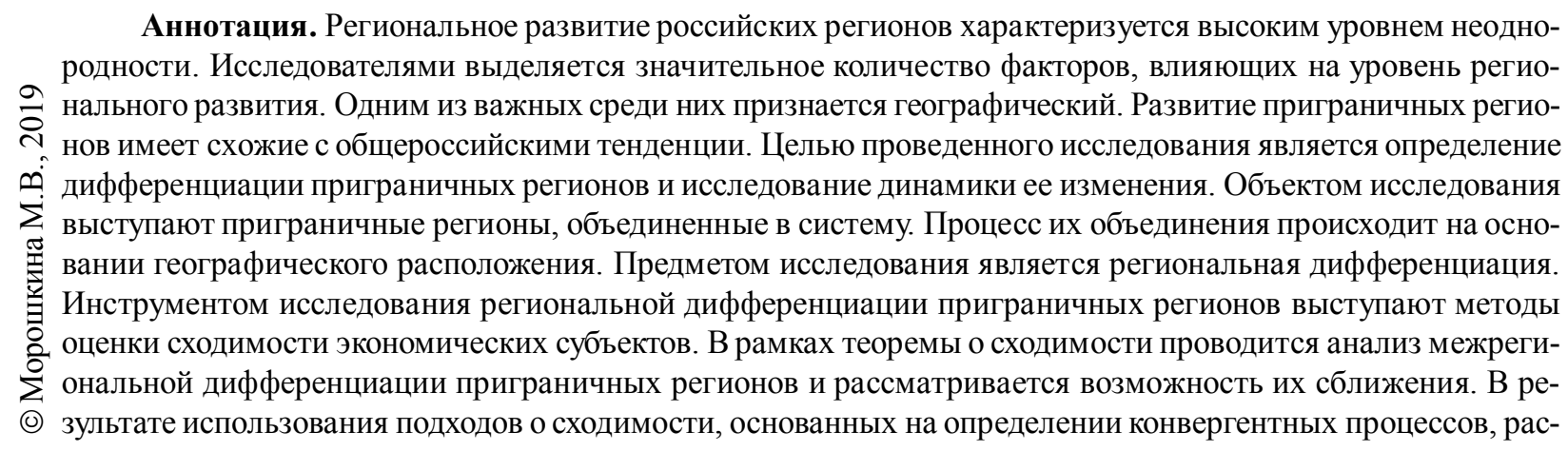


считывается коэффициент вариации. На базе расчетных значений коэффициента и его изменения оценивается возможность сближения приграничных регионов и анализируется процесс изменения межрегиональной дифференциации. Другим направлением, на основании которого происходит анализ неоднородности приграничных регионов, является определение коэффициента дифференциации, позволяющего определить уровень разрыва между полярными группами регионов. Поставленная в исследовании цель позволит оценить влияние географического положения на экономическое развитие и сформулировать направления экономической политики. Пространственная неоднородность приграничных регионов, определенная при помощи математического инструментария, может быть использована при написании Программы и Стратегии регионального развития, в рамках которых одним из конкурентных преимуществ будет являться расположение территории.

Ключевые слова: приграничные регионы, пространственная неоднородность, межрегиональная дифференциация, коэффициент вариации, $\alpha$-конвергенция, коэффициент дифференциации, отстающие приграничные регионы, лидирующие приграничные регионы.

Цитирование. Морошкина М. В. Географический фактор в региональном развитии // Вестник Волгоградского государственного университета. Экономика. - 2019. - Т. 21, № 4. - С. 90-98. - DOI: https://doi.org/ 10.15688/ek.jvolsu.2019.4.9

\section{Постановка проблемы}

Система международных экономических отношений мирового сообщества находится в постоянном процессе изменения. Происходящие в мировой экономике и странах мирового сообщества перемены оказывают влияние на большинство экономических и социальных процессов развития экономики отдельных государств.

Стратегические и программные документы развития национальной экономики большое значение отводят территориям, занимающим приграничное положение. Геополитическое положение приграничных территорий влияет на большинство направлений экономического роста и способствует формированию и развитию внешнеэкономических отношений [Андриченко, 2017].

Развитие экономических отношений, трансграничных связей с территориями других государств определяет уровень внешнеэкономического сотрудничества, кооперации и международной экономической интеграции. Россия является государством, имеющим множество различных по развитию приграничных территорий. Более половины субъектов РФ находятся в приграничных отношениях с другими государствами [Вардомский и др., 2010]. Наличие большого количества приграничных территорий необходимо учитывать при составлении программных документов. Отдельное внимание стоит уделить дифференциации в уровне развития государств, с кото- рыми граничат российские регионы, в результате которой наблюдаются отличия по различным характеристикам.

Таким образом, основной целью исследования является проведение анализа регионального развития приграничных территорий сопредельных государств. В рамках поставленной цели объектом исследования являются приграничные регионы, а предметом исследования уровень межрегиональной дифференциации данных территорий.

\section{Обзор литературы}

Экономическое развитие - это процесс, который зависит от множества факторов. Исследователи активно изучают влияние последних на динамику экономического роста. Современный период мировой экономики характеризуется высоким уровнем глобализационных процессов и увеличением интеграции экономик относительно друг друга. В результате сложившихся условий функционирования региональных систем особого внимания заслуживает фактор географического расположения территории. Региональные исследования довольно часто рассматривают взаимосвязь динамики развития территории и ее географического расположения.

Влияние фактора расположения рассматривается в классических работах по экономике. Понятие «географическое положение» введено в XIX в. в трудах К. Маркса и Ф. Энгельса [Блауг, 1994]. 
В дальнейшем осуществлялись различные попытки оценить влияние расположения на развитие экономического субъекта. В рамках исследований рассматривались экономические субъекты различного масштаба: начиная от производственного предприятия и его расположения [Леш, 1959] и заканчивая национальной экономикой.

Важной задачей в исследовании влияния географического расположения экономического субъекта является не только процесс установления фактора влияния, но и возможность оценить это влияние [Баранский Н.Н. (1881-1963), 1994]. В рамках оценки влияния расположения экономического субъекта, особого внимания заслуживают территории приграничного положения. Ввиду географической близости с другой национальной экономикой данные территории оказываются во власти двойного воздействия: с одной стороны, внутреннее влияние экономических процессов, которые определяют и взаимосвязи с другими регионами, и продвижение товаров и услуг на внутренний рынок, и развитие производственного сектора; с другой стороны, экономическое соседство с иной экономической системой, которое влияет на развитие экономических связей, внешнеэкономическое сотрудничество, развитие туристической отрасли и т. д. [Ткачев и др., 2016].

Влияние расположения региона на экономическое развитие, развитие промышленного производства, инвестиционную привлекательность и другие показатели определяется в рамках большинства работ современных исследователей [Дружинин, 2017; Морошкина, 2016].

Приграничные регионы имеют конкурентное преимущество в отношении ведения внешнеэкономической деятельности, однако данные территории являются сильно удаленными от экономических центров страны. [Осадчая и др., 2013].

Анализ приграничных территорий в рамках исследования уровня регионального развития основывается на положении о том, что приграничные регионы имеют ряд преимуществ, связанных с местоположением. Проблемы, преимущества и перспективы развития приграничных регионов широко обсуждаются в научной среде, акцентируя внимание на влиянии местоположения территории на динамику экономического роста. А.Н. Молостов отмечает, что приграничное расположение территории увеличивает возможность и необходимость межтерриториального сотрудничества, позволяющая на внутреннем и международном рынках позиционировать конкурентные преимущества и обосновывают целесообразность использования кластерного подхода для принятия стратегических решений в приграничных регионах [Молостов, 2013]. Подобный механизм позволяет оптимизировать процессы управления на основании приоритетных преимуществ, которые выявляются в процессе анализа.

В рамках исследования региональной экономики внимание отводится вопросам расположения различных по масштабу экономических систем. В данном контексте могут анализироваться такие экономические состояния: местоположение региона, расположение производства, удаленность от основных экономических центров государства или от границ. Большинство исследователей сходятся во мнении, что крупные экономические системы являются центрами притяжения других территорий, втягивая данные территории в свои экономические и производственные процессы [Кругман, 2005].

Немаловажное значение в вопросах регионального развития в целом и географического расположения в частности играет анализ неоднородности. Большинство территорий экономической системы имеют неравномерное и неодинаковое развитие, что вызывает дифференциацию. Для регионов приграничного направления неравномерность также является свойственной. Оценка такой ситуации может проводиться на основании теории и инструментария, которые позволяют оценить региональный разброс.

Исследования по региональной дифференциации могут быть разделены на несколько направлений [Гранберг и др., 2003; Гранберг и др., 2007]. С одной стороны, определяются коэффициенты региональной дифференциации по различным показателям. С другой стороны, исследуется оценка влияния различных экономических процессов на увеличение уровня региональной неоднородности [Гранберг, 1999; 1998]. Можно выделить ряд исследовательских работ, в которых анализируют- 
ся причины региональной неоднородности и оценивается уровень асимметрии. Фундаментальные работы по региональной дифференциации предлагают расчеты коэффициентов, индексов, на основании которых можно сделать вывод о степени неоднородности регионов - К. Джини, А. Тейла, Э.Б. Аткинсона [Gini, 1936; Theil, 1967; Atkinson, 1970].

В исследованиях мирового сообщества проблемы межрегиональной дифференциации и регионального неравенства также являются актуальными. На основании построения математических моделей и оценок определяется уровень региональной асимметрии. В работах Р. Барро и Х. Сала-и-Мартин региональные различия анализируются на основании построения моделей экономического роста [Barro et al., 1991; 1995].

Территория Российской Федерации имеет высокий уровень региональной неоднородности. Вопросам регионального и территориального развития посвящено большое количество исследований. Региональная асимметрия рассматривается в контексте влияния различных факторов. Одним из направлений является анализ различных процессов на уровень региональных различий [Мартынов, 2009]. В рамках ряда направлений анализируется влияние отдельных факторов на уровень развития регионов и изменение региональной дифференциации [Пионьковецкая, 2017].

\section{Методология}

В рамках данного исследования проводится анализ неоднородности экономического развития приграничных российских регионов.

Аналитическим аппаратом, который способен оценить уровень дифференциации приграничных регионов, является коэффициент вариации (Coefficient of Variation, CV), позволяющий оценить неравенство исследуемых субъектов.

Коэффициент вариации определяется по следующей формуле 1:

$$
\sigma_{t}=C V=\frac{\sigma}{x_{\mathrm{cp}}}
$$

где $\sigma$ - среднеквадратическое отклонение случайной величины (ф. 2):

$$
\sigma=\sqrt{\frac{1}{n} \sum_{i=1}^{n}\left(x_{i}-x_{\mathrm{cp}}\right)^{2}}
$$

где $x_{\text {ср }}$ - среднее значение показателя; $x_{i}$ - показатель уровня развития; $i$-регион; $i=1, \ldots n$-количество исследуемых регионов.

Анализ рассеивания в региональном разрезе и определение сходимости может происходить в результате использования теоремы о сходимости [Barro et al., 1991; 1995].

В методологическом аспекте выделяют $\delta$-конвергенцию, которая обусловливает процесс сокращения разброса показателей, в региональном анализе. Для подтверждения наличия $\delta$-конвергенции необходимо выполнение условия, которое определяет снижение коэффициента вариации в конечный период, по отношению к коэффициенту вариации в начальный период (ф. 3):

$$
\sigma_{t+T}<\sigma_{t}
$$

Одним из нескольких вариантов исследования неоднородности является определение разрыва между исследуемыми экономическими субъектами. Подобный вариант анализа позволяет рассмотреть общее состояние исследуемых объектов, выделить лидирующие и отстающие регионы и проанализировать их соотношение.

Определение разрыва между лидирующими и отстающими регионами может быть определено на основании расчета коэффициента дифференциации, который может быть рассчитан по формуле 4:

$$
K_{p r}=\frac{I p r_{\text {lid }}}{I p r_{\text {otst }}}
$$

Использование формулы (1) при оценке коэффициента дифференциации позволит определить разрыв между наиболее экономически развитым приграничным регионом и наиболее не развитым.

В результате использования указанных подходов проанализированы показатели ВРП на душу населения, среднедушевые доходы населения, объемы промышленного производства. Полученные результаты позволят сравнить динамику и уровень региональной неоднородности. 


\section{Результаты}

В рамках поставленной в исследовании цели были проанализированы приграничные регионы по показателям ВРП на душу населения и среднедушевые доходы населения. В рамках проведенного анализа были представлены 2 направления исследования. Одним из них является выделение группы лидирующих приграничных регионов и группы отстающих регионов и определение разрыва между ними. Другим направлением является определение коэффициента вариации, позволяющего определить наличие $\sigma$-конвергенции и сделать вывод о сокращении межрегиональной дифференциации и сближении исследуемых приграничных регионов.

ВРП на душу населения. Показатель ВРП на душу населения для приграничных регионов был рассмотрен в рамках периода 1995-2017 гг. и представлен в таблице 1.

На основании представленной методологии расчета коэффициента вариации были произведены расчеты по приграничным регионам и получены следующие значения коэффициента вариации (табл. 2).

Проведенные расчеты позволили проанализировать уровень дифференциации российских приграничных регионов и определить возможности их сходимости. В результате использования положений теоремы о сходимости необходимо проверить выполнение условия (3). Поведение коэффициента вариации в рамках исследуемого периода представлено на рисунке.

В результате проведенного анализа изменения коэффициента вариации и выполнения условия сходимости (3) можно говорить о процессе расхождения приграничных российских регионов и увеличении неоднородности (см. рисунок).

Анализ неоднородности российских приграничных регионов определил наличие региональной дифференциации. Процесс неоднородности, наблюдаемый по российским регионам в целом и по приграничным регионам в частности, во многом зависит от уровня экономического развития территории и наличия производственных мощностей [Морошкина, 2016]. Исследование приграничных регионов и их ранжирование по показателю ВРП на душу населения также соответствует общероссийским тенденциям. Регионы, которые имеют максимальные показатели ВРП на душу населения за 2017 г., характеризуются наличием природно-ресурсной базы и высоким уровнем развития производственного сектора.

Таблица 1

Фрагмент таблицы изменения показателя ВРП на душу населения приграничных регионов, рубли *

\begin{tabular}{|c|c|c|c|c|c|c|c|}
\hline \multirow{2}{*}{ Субъекты } & \multicolumn{7}{|c|}{ Годы } \\
\hline & 1995 & 1999 & 2003 & 2007 & 2011 & 2015 & 2017 \\
\hline $\mathbf{P \Phi}$ & 9566,3 & 28492,1 & 74884,9 & 195819,0 & 317515,3 & 449097,9 & 510253,1 \\
\hline Белгородская область & 8598,7 & 22611,1 & 50284,0 & 156225,0 & 331010,0 & 447619,7 & 506420,9 \\
\hline Брянская область & 5272,3 & 12448,9 & 31942,3 & 78518,8 & 137187,1 & 221080,0 & 253100,4 \\
\hline Воронежская область & 6600,0 & 15797,2 & 42361,8 & 94849,5 & 203575,5 & 345566,8 & 370610,4 \\
\hline Курская область & 7137,8 & 18059,4 & 46109,9 & 111348,0 & 203676,0 & 301242,5 & 346340,2 \\
\hline Смоленская область & 6692,4 & 18916,7 & 47238,6 & 94432,4 & 184184,9 & 266927,2 & 296289,6 \\
\hline Республика Карелия & 10245,5 & 26297,5 & 65443,1 & 157959,0 & 241688,0 & 335944,5 & 404487,6 \\
\hline Архангельская область & 9336,3 & 25077,5 & 78436,0 & 212908,0 & 360165,9 & 532533,7 & 640787,5 \\
\hline Калининградская область & 5658,2 & 17096,2 & 49120,4 & 153964,0 & 255217,8 & 359639,7 & 421479,2 \\
\hline
\end{tabular}

Примечание. Составлено автором по данным Росстата. * - данные представлены через интервал 3 года за период с 1995 по 2015 г. и за 2017 год.

Таблииа 2

Расчет коэффициента вариации по приграничным регионам России

\begin{tabular}{|l|c|c|c|c|c|c|c|}
\hline Годы & 1995 & 1999 & 2003 & 2007 & 2011 & 2015 & 2017 \\
\hline $\begin{array}{l}\text { Коэффициент } \\
\text { вариации }\end{array}$ & 0,63 & 0,72 & 0,86 & 0,84 & 0,86 & 0,84 & 0,81 \\
\hline
\end{tabular}

Примечание. Составлено автором по данным Росстата. 
М.В. Морошкина. Географический фактор в региональном развитии

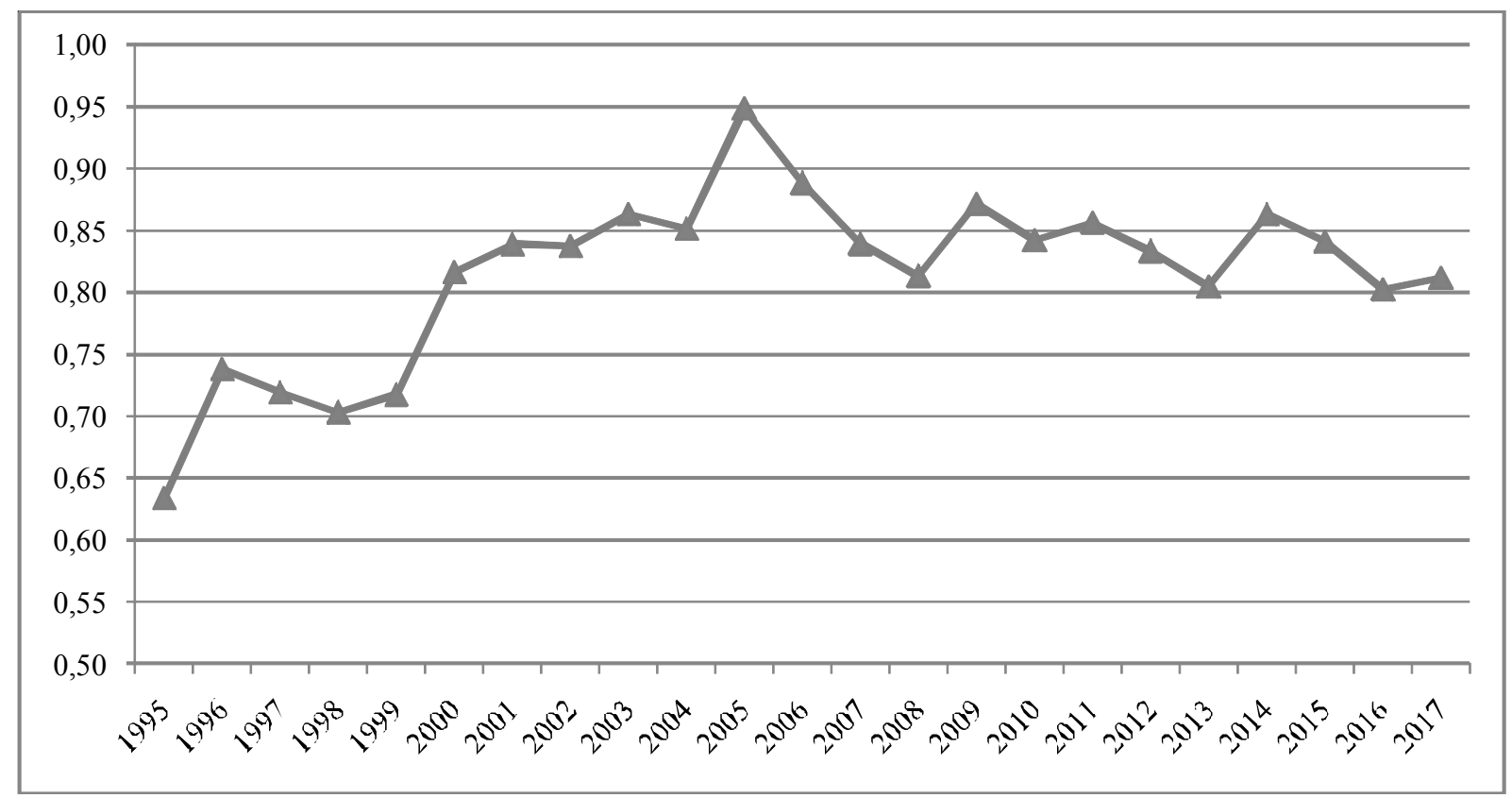

Рисунок. Изменение коэффициента вариации, рассчитанного по приграничным регионам России

Примечание. Составлено автором по данным Росстата.

Стоит отметить, что среди приграничных регионов встречаются территории, которые и в общероссийском списке занимают отстающие позиции. На уровне приграничных регионов эти территории также находятся на отстающих позициях (табл. 3).

Результатом использования формулы (1) является оценка коэффициента дифференциации, позволяющая определить разрыв между исследуемыми объектами в рассматриваемой совокупности (см. табл. 4).

Проведенный анализ оценки неравномерности на основании расчета коэффициента диф- ференциации и определения регионов с максимальным и минимальным значением показал, что приграничные регионы повторяют тенденции российских регионов. Лидирующим регионом в рамках совокупности приграничных регионов была определена Тюменская область, что в исследованиях автора по российским регионам также было отмечено. Регионом с самым наименьшим значением исследуемого показателя является Республика Ингушетия, что также соответствует общероссийским тенденциям, отмеченным большинством исследователей в рамках научных публикаций.

Таблица 3

Ранжирование приграничных регионов по показателю ВРП на душу населения 2017 г., рубли

\begin{tabular}{|l|r|}
\hline \multicolumn{1}{|c|}{ Приграничные регионы } & 2017 г. \\
\hline Отстающие регионы & 114844,1 \\
\hline Республика Ингушетия & 125471,2 \\
\hline Чеченская & 160077,0 \\
\hline Кабардино-Балкарская Республика & 160110,5 \\
\hline Карачаево-Черкесская Республика & 164978,4 \\
\hline г. Севастополь \\
\hline \multicolumn{2}{|c|}{ Лидирующие регионы } \\
\hline Республика Саха (Якутия) & 951220,2 \\
\hline Магаданская область & 1088347,4 \\
\hline Чукотский автономный округ & 1386085,3 \\
\hline Сахалинская область & 1577910,3 \\
\hline Тюменская область & 1900322,7 \\
\hline
\end{tabular}

Примечание. Составлено автором по данным Росстата. 
Оценка разрыва между приграничными регионами России

\begin{tabular}{|l|r|r|r|r|r|r|r|r|r|}
\hline Годы & \multicolumn{1}{|c|}{1995} & \multicolumn{1}{c|}{1998} & \multicolumn{1}{c|}{2001} & \multicolumn{1}{c|}{2004} & \multicolumn{1}{c|}{2007} & \multicolumn{1}{c|}{2010} & \multicolumn{1}{c|}{2013} & 2016 & 2017 \\
\hline $\mathrm{cp}$ & 8422,0 & 14599,9 & 44319,3 & 84738,5 & 162680,7 & 235421,9 & 332334,9 & 422894,5 & 450523,7 \\
\hline $\max$ & 34421,4 & 63325,5 & 232236,3 & 465848,8 & 831305,3 & 977256,0 & 1402915,6 & 1627945,9 & 1900322,7 \\
\hline $\min$ & 1940,4 & 3435,8 & 8000,7 & 12975,9 & 41340,7 & 48239,2 & 91646,1 & 106756,6 & 114844,1 \\
\hline $\mathrm{K}$ & 17,7 & 18,4 & 29,0 & 35,9 & 20,1 & 20,3 & 15,3 & 15,2 & 16,5 \\
\hline
\end{tabular}

Примечание. Составлено автором по данным Росстата.

\section{Выводы}

В результате проведенного исследования дифференциации российских приграничных регионов были выявлены тенденции расхождения или дивергенции, что в общем виде повторяет тенденции российских регионов. Большинство приграничных регионов имеют различные условия ведения хозяйственной и экономической деятельности, различные производственные возможности и отличаются по наличию природно-ресурсного потенциала. Подобные расхождения не могли не сказаться на уровне развития приграничных регионов. В рамках проведенного анализа последние были проклассифицированы по показателю ВРП на душу населения. Важным результатом, также подтверждающим общероссийские тенденции, является вывод о том, что в пределах массива приграничных регионов лидирующие позиции занимают территории, имеющие природно-ресурсный потенциал и развитые производственные мощности. Данное обстоятельство является значимым для экономического развития приграничных регионов. Наличие выгодного географического положения лишь усиливает позиции регионов, имеющих лидирующиепозиции. Для отстающих регионов приграничное положение является фактором, тормозящим развитие территории. Географическое положение для таких территорий рассматривается как фактор удаленности от основных региональных рынков страны и тем самым сокращает доступность для товаропроизводителей.

Рассматривая приграничное положение различных российских регионов, можно говорить о неодинаковом влиянии фактора «приграничности» на каждый из них. Для одних регионов этот фактор стимулирует экономическое развитие, порождая увеличение объемов производства. Для других ситуация является противоположной и данный фактор сокращает производственные объемы.
В результате полученных выводов можно говорить о неоднозначном влиянии приграничного положения на экономическое развитие территории. Стимулирование экономического роста регионов должно учитывать конкурентные преимущества отдельной территории и опираться на факторы экономического роста. Стратегические и программные документы должны учитывать специфические особенности территории и конкурентные преимущества регионов, позволяя формировать условия для экономического роста.

\section{ПРИМЕЧАНИЕ}

${ }^{1}$ Исследование выполнено в рамках госзадания по теме АААА-А19-119010990087-1 «Выявление синергетических закономерностей региональных социо-эколого-экономических систем и моделирование динамических процессов устойчивого развития в многокомпонентных системах различной природы».

The reported study was carried out in the framework of the state assignment on the issue AAAA-A19-119010990087-1 "Identifying Synergetic Regularities of Regional Socio-Ecological and Economic Systems and Modeling Dynamic Processes of Sustainable Development in Multi-Component Systems of Different Nature".

\section{СПИСОК ЛИТЕРАТУРЫ}

Андриченко, Л. В. Стратегия государственного регионального развития Российской Федерации: правовые основы / Л. В. Андриченко // Журнал российского права. - 2017. - № 5. - С. 5-18.

Баранский Н.Н. (1881-1963) // Народонаселение : Энциклопедический словарь / гл. ред. Г. Г. Меликьян. - М. : Большая Рос. энцикл., 1994. $640 \mathrm{c}$.

Блауг, М. Путеводитель по «Капиталу» / М. Блауг // Экономическая мысль в ретроспективе = Economic Theory in Retrospect. - М. : Дело, 1994. $-627 \mathrm{c}$. 
Вардомский, Л. Б. Внешнеэкономическая деятельность регионов России : учеб. пособие / Л. Б. Вардомский, Е. Е. Скатерщикова.-М. : КНОРУС, 2010.$448 \mathrm{c}$.

Гранберг, А. Г. Многорегиональные системы: экономико-математические исследования / А. Г. Гранберг, В. И. Суслов, С. А. Суспицин. - Новосибирск : Сиб. науч. изд-во, 2007. -371 с.

Гранберг, А. Г. Валовой региональный продукт: межрегиональные сравнения и динамика / А. Г. Гранберг, Ю. С. Зайцева. - М. : СОПС, 2003. - $117 \mathrm{c}$.

Гранберг, А. Г. Межрегиональное экономическое сотрудничество сопредельных стран / А. Г. Гранберг // Регионы в системе внешнеэкономических связей Российской Федерации / под общ. ред. С. Г. Горшенина. - Оренбург : Оренбург. кн. изд-во, 1998. - $307 \mathrm{c.}$

Гранберг, А. Г. Регионы в экономическом пространстве России / А. Г. Гранберг // Экономика Северо-Запада: проблемы и перспективы. - 1999. - № 2. - С. 4-12.

Дружинин, П. В. Особенности развития приграничных регионов / П. В. Дружинин // Регионология $=$ Regionology. -2017 . - № 2. C. 200-216.

Кругман, П. Пространство: последний рубеж / П. Кругман // Пространственная экономика. - 2005. №3. - С.121-126.

Мартынов, А. С. Применение интуитивных методов в процессе прогнозирования социально-экономического развития регионов / А. С. Мартынов // Региональная экономика: теория и практика. - 2009. - № 39 (132). - С. 23-28.

Молостов, А. Н. Политико-экономическая кластеризация ресурсов приграничных регионов как необходимое условие безопасности Российской Федерации / А. Н. Молостов // Бизнес в законе. Экономико-юридический журнал. - 2013. - № 5. - С. 292-296.

Морошкина, М. В. Дифференциация российских регионов по уровню экономического развития / М. В. Морошкина // Проблемы прогнозирования. - 2016. - №4 (157). - С. 109-115.

Осадчая, О. П. Основные формы организации приграничного сотрудничества : монография / О. П. Осадчая, Д. В. Ремизов. - Рубцовск : Рубцов. индустр. ин-т, 2013. - 155 с.

Ткачев, С. А. Приграничное сотрудничество в региональном социально-экономическом развитии: теория, российская практика / С. А. Ткачев, Д. А. Болотов, Н. М. Межевич // Региональные проблемы преобразования экономики. - 2016. - № 1. - С. 87-93.

Atkinson, A. B. On the Measurement of Inequality / A. B. Atkinson // Journal of Economic Theory.-
1970. - № 2 (3). - P. 244-263. - DOI: 10.1016/ 0022-0531(70)90039-6.

Barro, P. J. Convergence Across States and Region / P. J. Barro, X. Sala-J-Martin // Brooking Papers on Economy Activity. - 1991. - № 1. - P. 58-107.

Barro, P. J. Economic Growth / P. J. Barro, X. SalaJ-Martin. - Massachusetts : MIT Press, Cambridge, 1995. - $200 \mathrm{p}$.

Gini, C. On the Measure of Concentration with Special Reference to Income and Statistics / C. Gini // Colorado College Publication, General Series. 1936. - № 208. - P. 73-79.

\section{REFERENCES}

Andrichenko L.V. Strategiya gosudarstvennogo regionalnogo razvitiya Rossiyskoy Federatsii: pravovye osnovy [Strategy of the State Regional Development of the Russian Federation: Legal Bases]. Zhurnal rossiyskogo prava [Journal of Russian Law], 2017, no. 5, pp. 5-18.

Baranskiy N.N. (1881-1963). Melikyan G.G., ed. Narodonaselenie: Entsiklopedicheskiy slovar [Population. Encyclopedic Dictionary]. Moscow, Bolshaya Rossiyskaya entsiklopediya, 1994. $640 \mathrm{p}$.

Blaug M. Putevoditel po «Kapitalu» [Guide to "Capital"]. Ekonomicheskaya mysl v retrospektive [Economic Theory in Retrospect]. Moscow, Delo Publ., 1994. 627 p.

Vardomskiy L.B., Skatershchikova E.E. Vneshneekonomicheskaya deyatelnost regionov Rossii: uchebnoe posobie [Foreign Economic Activity of Regions of Russia. Textbook]. Moscow, KNORUS Publ., 2010. 448 p.

Granberg A.G., Suslov V.I., Suspitsin S.A. Mnogoregionalnye sistemy: ekonomikomatematicheskie issledovaniya [Multiregional Systems: Economic-Mathematical Studies]. Novosibirsk, Sibirskoe nauchnoe izd-vo, 2007. $371 \mathrm{p}$.

Granberg A.G., Zaytseva Yu.S. Valovoy regionalnyy produkt: mezhregionalnye sravneniya $i$ dinamika [Gross Regional Product: Interregional Comparisons and Dynamics]. Moscow, SOPS, 2003. $117 \mathrm{p}$.

Granberg A.G. Mezhregionalnoe ekonomicheskoe sotrudnichestvo sopredelnykh stran [Interregional Economic Cooperation of the Adjacent Countries]. Gorshenin S.G., ed. Regiony v sisteme vneshneekonomicheskikh svyazey Rossiyskoy Federatsii [Regions in the System of Foreign Economic Relations of the Russian Federation]. Orenburg, Orenburgskoe knizhnoe izd-vo, 1998. 307 p. 


\section{РЕГИОНАЛЬНАЯ ЭКОНОМИКА}

Granberg A.G. Regiony v ekonomicheskom prostranstve Rossii [Regions in Economic Space of Russia]. Ekonomika Severo-Zapada: problemy i perspektivy [Economy of the NorthWest: Issues and Prospects of Development], 1999, no. 2, pp. 4-12.

Druzhinin P.V. Osobennosti razvitiya prigranichnykh regionov [Features of the Development of Border Regions]. Regionologiya [Regionology], 2017, no. 2 , pp. $200-216$.

Krugman P. Prostranstvo: posledniy rubezh [Space: Last Boundary]. Prostranstvennaya ekonomika [Spatial Economics], 2005, no. 3, pp.121-126.

Martynov A.S. Primenenie intuitivnykh metodov v protsesse prognozirovaniya sotsialnoekonomicheskogo razvitiya regionov [The Use of Intuitive Methods in the Process of Forecasting the Socio-Economic Development of Regions]. Regionalnaya ekonomika: teoriya i praktika [Regional Economics: Theory and Practice], 2009, no. 39 (132), pp. 23-28.

Molostov A.N. Politiko-ekonomicheskaya klasterizatsiya resursov prigranichnykh regionov kak neobkhodimoe uslovie bezopasnosti Rossiyskoy Federatsii [Political and Economic Clustering of Resources of Border Regions as a Necessary Condition for the Security of the Russian Federation]. Biznes $v$ zakone. Ekonomiko-yuridicheskiy zhurnal [Business in Law], 2013, no. 5, pp. 292-296.

Moroshkina M.V. Differentsiatsiya rossiyskikh regionov po urovnyu ekonomicheskogo razvitiya [Differentiation of Russian Regions on the Level of Economic Development]. Problemy prognozirovaniya [Studies on Russian Economic Development], 2016, no. 4 (157), pp.109-115.

Osadchaya O.P., Remizov D.V. Osnovnyye formy organizatsii prigranichnogo sotrudnichestva: monografiya [Main Forms of Organizing CrossBorder Cooperation. Monograph]. Rubtsovsk, Rubtsovskiy industrialnyy institut, 2013. 155 p.

Tkachev S.A., Bolotov D.A., Mezhevich N.M. Prigranichnoe sotrudnichestvo $\mathrm{v}$ regionalnom sotsialno-ekonomicheskom razvitii: teoriya, rossiyskaya praktika [Border Cooperation in Regional Social and Economic Development: Theory, Russian Practice]. Reginalnye problemy preobrazovaniya ekonomiki [Regional Problems of Transforming the Economy], 2016, no. 1, pp. 87-93.

Atkinson A.B. On the Measurement of Inequality. Journal of Economic Theory, 1970, no. 2 (3), pp. 244-263. DOI: 10.1016/0022-0531(70)90039-6.

Barro P.J., Sala-J-Martin X. Convergence Across States and Region. Brooking Papers on Economy Activity, 1991, no. 1, pp. 58-107.

Barro P.J., Sala-J-Martin X. Economic Growth. Massachusetts, Cambridge, MIT Press, 1995. $200 \mathrm{p}$.

Gini C. On the Measure of Concentration with Special Reference to Income and Statistics. Colorado College Publication, General Series, 1936, no. 208, pp. 73-79.

\section{Information About the Author}

Marina V. Moroshkina, Candidate of Sciences (Economics), Researcher, Institute of Economics of the Karelian Scientific Center of the Russian Academy of Sciences, Prosp. Nevskogo, 50, 185030 Petrozavodsk, Russian Federation, Maribel74@mail.ru, https://orcid.org/0000-0001-6520-4248

\section{Информация об авторе}

Марина Валерьевна Морошкина, кандидат экономических наук, научный сотрудник, Институт экономики Карельского научного центра РАН, просп. А. Невского, 50, 185030 г. Петрозаводск, Российская Федерация, Maribel74@mail.ru, https://orcid.org/0000-0001-6520-4248 